\title{
Cultural responses to primitive needs
}

\author{
N. Baker \\ The Martin Centre for Architectural and Urban Studies, \\ University of Cambridge, UK
}

\begin{abstract}
This paper proposes that our responses to the environment are influenced in part by our contemporary culture and in part by the genetic background of our primitive survival. Evidence of primitive responses is cited from the fields of thermal comfort, and visual comfort. Strong psychological influences are identified. The need for access and reference to nature in modern life is proposed and the possibilities of other substitutes is explored.

Keywords: adaptive, ambience, artificial nature, behaviour, comfort, environment, genetic, primitive, nature, synthetic nature.
\end{abstract}

\section{Introduction}

Although we spend $95 \%$ of our time indoors, we are really outdoor animals. The forces that have selected the genes of contemporary man are found outdoors in the plains, forests and mountains, not in air-conditioned bedrooms and at ergonomically designed workstations. Fifteen generations ago, a period of little consequence in evolutionary terms, most of our ancestors would spend the majority of their waking hours outdoors, and buildings would primarily provide only shelter and security during the hours of darkness. Even when inside, the relatively poor performance of the building meant that the indoor conditions closely tracked the outdoor environment.

Furthermore, many of the activities that played a vital role in survival demanded an intimate knowledge of the climate, the weather and the landscape. Agriculture is an obvious example; rainfall, frosts, wind and their interaction with the landscape - shelter, drainage, pests etc, constantly reinforced man's link with nature.

Robert Winston [1] points out that whilst it is commonly accepted that our physical attributes derive from our primitive ancestors, it is less widely 
recognised that our behavioural traits may also. He refers to these as instincts, and uses the primitive model to explain our emotions in relation to families, religion and society. By implication, he is saying that certain behavioural responses are genetically determined and that we could expect these responses to change only by evolutionary mechanisms with a time scale of many hundreds of generations. In this paper we extend the argument to explain our response to our present day built environment - which differs even more from our primitive origins than do our contemporary social and family structures.

It is an appealing thought that there is some deep and causal relationship between our adjustment of a thermostat and the action to take refuge from the winter night in a cave; between the tolerance of lower colour temperature light sources at night and the lighting of the multi purpose fire at the entrance to the cave following sunset; between the multi-billion pound industry in cut-flowers and houseplants, and the daily surveillance by primitive man of natural landscape and vegetation. But is there any evidence to support this link, and if it is proven, how will this knowledge help us to understand and improve our modern environment?

\section{Thermal comfort}

Our modern indoor lifestyle is consuming massive amounts of fossil energy, simply to isolate ourselves from the forces that moulded us. In the last 25 years we have consumed as much fossil energy as in the history of man. Undoubtedly our drive to engineer the environment is broadly the same urge that made primitive hunter gatherer first improve his cave, stockpile food and fuel, then cultivate plants, domesticate animals, form cooperative groups, trade and so on. It seems though, that our technological momentum has caused us to over-shoot; to deliver too much of a good thing, to interpret the life-saving instinct to mitigate the cold by throwing another log on the fire as the need to eliminate all thermal sensation at any cost.

To explore this question, we will first turn to the topic of thermal comfort, since both the physiological and behavioural aspects have been well researched. Temperature, or rather the heat balance of the body that it controls, is one of the key environmental parameters affecting survival. We would expect it to be one of the most vital responses hard-wired in our genes. With civilization and development it has lost nothing in its importance, for in struggling to isolate ourselves from the natural variations in temperature, energy for heating and cooling buildings has become the largest single energy end use.

The most essential characteristic of the outdoor environment, is its variability. There is variability on different time scales - daily and annual cycles as well as the quasi-random nature of weather, and on different scales of space ranging from human scale to global scale. The consensus view, that supports a massive heating, ventilating and air-conditioning industry, is that the engineer's proper mission is to provide a stable, optimised environment, independent of the natural world outside. 
However, this is being challenged. More than twenty-five years ago, Lisa Heschong [2], in her highly original work "Thermal Delight" decried thermal uniformity. A decade later, this time as a result of rigorous field studies, Schiller [3] concluded that"...people voting with extreme [thermal] sensations are not necessarily dissatisfied". Since then many field studies have confirmed that thermal variation is tolerated, and in many cases enjoyed.

\subsection{Thermal comfort: the two models}

We have then, two schools of thought - the conventional view that thermal comfort is best described by thermal neutrality brought about by a steady state heat balance, and those that believe that thermal comfort can be achieved within a range of thermal sensations, provided adaptive behaviour is possible. The former school, based on responses of subjects in climate chambers, is epitomised by the work of Fanger [4], whilst the latter uses evidence from subjects in real buildings, typified by the work of Humphreys and Nicol [5]

Few would suggest that either represents bad science, yet they seem to reach significantly different conclusions. Why is this? One explanation would come as no surprise, that people behave differently in different contexts. It is not surprising that the subject, who has been told how to dress, been told how to sit, been told what task to do, in an unfamiliar climate chamber with no windows to open or warm radiator to draw closer too, responds differently from a person working in their study at home. The latter knows that there is a cold beer in the fridge or a warm sweater if needed. This has been tested directly by Oseland [6], who observed that the same group of subjects when tested in three contexts climate chamber, workplace and their home became progressively more tolerant - accepting winter comfort temperatures $3^{\circ} \mathrm{K}$ lower than in the climate chamber, with an intermediate value in the workplace.

The key difference between the climate chamber and the real working or living environment is that in the second case the subject has a range of actions available to him or her that will mitigate the non-neutral thermal sensation. We refer to these actions as adaptive behaviour, and the facility to carry them out as adaptive opportunity.

\subsection{Field studies}

The role of adaptive behaviour in achieving thermal comfort has received considerable attention in the last few years and the importance of adaptive opportunity (figure 1) has been identified, Heerwagen [7],Bordass [8], Baker and Standeven [9]. This is the real and perceived freedom to make adjustments to the local environment (open windows, deploy shades) or to one's own status (remove clothing, move to cooler part of the room, alter posture). Work by Guedes [10] shows that in a large sample of office workers in Portugal, occupants felt more satisfied with the thermal conditions where there were openable windows, even when the opportunity for opening them was not taken. This strongly suggests that there is a psychological as well as physical aspect to adaptive behaviour. We will return to this issue later. 

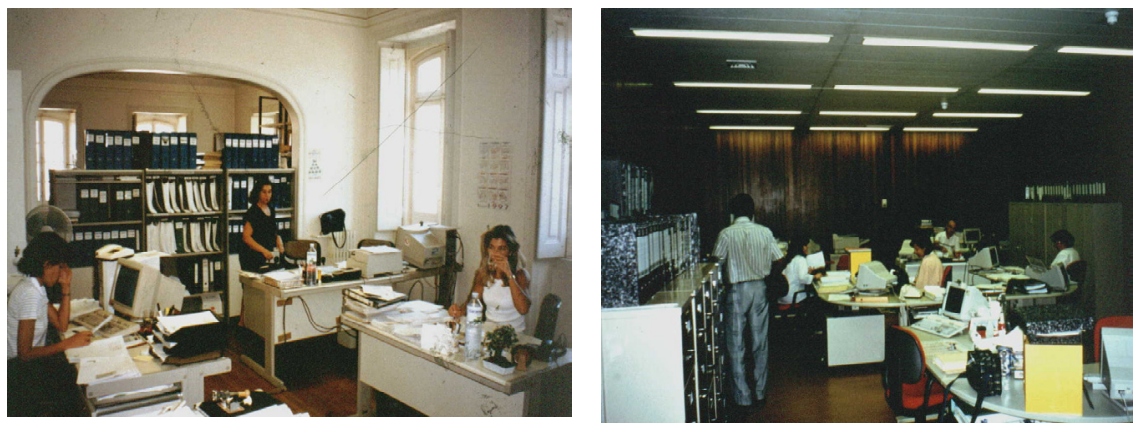

Figure 1: Two office environments in Lisbon showing good (left) and poor (right) adaptive opportunity.

Even in more extreme climates, adaptive actions are often sufficient to achieve thermal satisfaction for wide ranges of thermal conditions. In a study in the Sudan, Merghani [11] observed that occupants of courtyard houses utilised the spatial and temporal range of temperatures available in the rooms and courtyard to maximise their comfort. Figure 2 shows that the occupant is highly selective; the temperature chosen by an occupant remaining close to the predicted comfort temperature, throughout the day.

The migration was not solely comfort-seeking, but was also for practical and social functions. However, habitual use of the house in this way, has a mutually reinforcing effect on these functions, and leads to increased overall satisfaction. This supports the notion that thermal comfort is a strongly contextual and holistic phenomenon. It explains too, why under the closely controlled conditions of a test chamber, subjects respond in a completely different way.

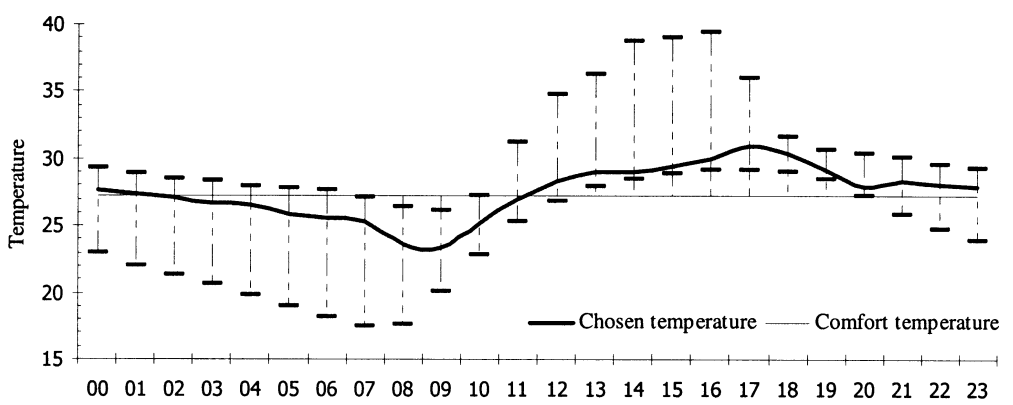

Figure 2: Chosen temperature (heavy line), i.e. the temperature at the location of the occupant throughout the day, with the range of temperatures existing in the building at each hour indicated by the bar. Note the chosen temperature follows the comfort temperature almost as closely as possible Merghani, [11]. 


\section{Outdoor comfort}

In a study in Cambridge by Nikolopoulou et al. [12], it was found that people sitting outdoors in public places, had greatly increased tolerance of non-neutral conditions, compared to what we would expect for indoor comfort. Typically, satisfaction was around $85 \%$ compared with a predicted value of $35 \%$. Note that the predicted satisfaction, using Fanger's heat balance model, had already taken account of clothing level and metabolic rate, suggesting that there must be a strong psychological factor to account for the wide difference between the predicted and the actual satisfaction. She also observed significantly higher satisfaction when people were free to suit themselves when to leave, than when they were waiting to meet someone. This indicates that the element of choice has a significant and measurable effect.

The increase in tolerance was noticeably greater than is found inside buildings, even when they are regarded to have good adaptive opportunity. Could this be because the subjects are in outdoor and "natural" surroundings? Nicolopoulou also found that for subjects suffering from overheating discomfort in a sunlit street, where there was no natural landscape and little opportunity to seek shade, their increased tolerance was reduced.

These three examples certainly demonstrate adaptive behaviour, but they do not prove that it is essential for the environmental variance to which the subject responds to be "natural", although the increased tolerance in the latter case, certainly points in that direction.

\section{The luminous environment}

Our sensitivity to light is very different from our sensitivity to heat. Light in itself is rarely life-threatening. However, in its role as a carrier of information, it may well become critical to survival. It is not difficult to think of cases where this is so, for both primitive and modern man. Natural light also signals the diurnal cycle of rest and activity, preparing the human for tasks which are most definitely critical to survival. It is well known that exposure to natural cycle of daylight is instrumental in synchronising the body by the suppression of the hormones melatonin and seratonin.

But do we find responses to the luminous environment that are directly analogous to the thermal environment? A study carried out by Parpairi [13] in Cambridge showed an unexpected result. She studied user responses to different daylight conditions in a number of university libraries. Two cases are shown in figure 3 below, one, in a study carrel where the illumination is of high technical quality (glare free diffuse light without the distraction of high contrast), and another close to the window where conditions varied strongly with the weather conditions and in particular the presence of sunlight.

Her findings show that the preferred condition was the second. Users found that they enjoyed the sunlit view of the River Cam, and if the glare became unbearable, they could retreat into a shaded part of the room (seen on the left of the picture). The building offered adaptive opportunity and in spite of strong 
stimuli of a natural origin, occupants reported a high level of satisfaction. This case does seem to be closely analogous with enhanced levels of thermal satisfaction under similar natural stimuli. However, it is more complex because of the far greater information carrying capacity of light. It is interesting to speculate if the result would have been the same had the idyllic river-scene been replaced by a car-park or rubbish dump.

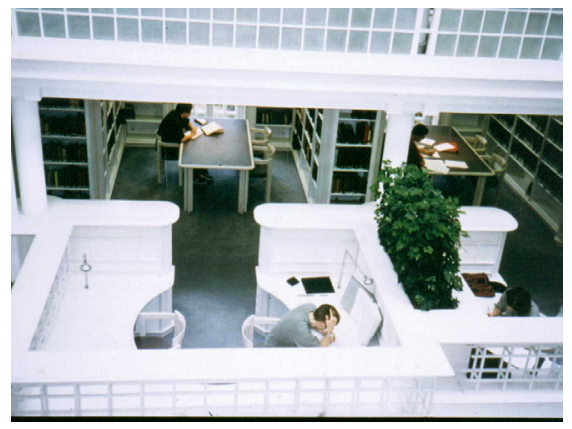

Figure 3: Comparison of occupant response to different daylight environments in two libraries.

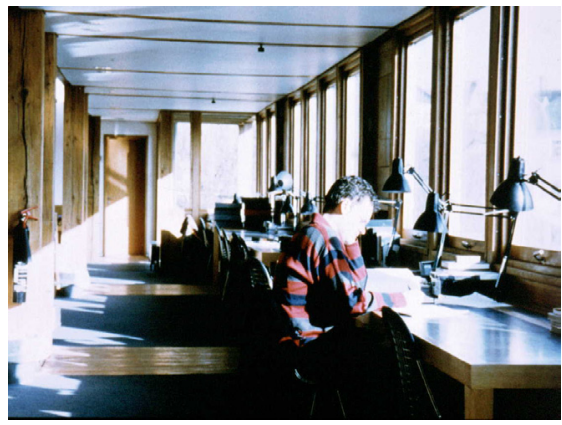

Clearly the information carried is important, even when it does not relate to the central task. We are dealing with ambience here, and it seems that ambience associated with nature is highly valued.

A striking and much quoted study carried out by Ulrich [14] investigated the impact of daylit views on patients recovering from surgery. He showed that patients recovered more rapidly when able to view a middle distance natural scene including trees, than when viewing a blank wall (Table 1).

Table 1: Comparison of requested analgesic doses per patient for wall view and tree-view patients; 46 patients between 2 and 5 days after surgery - R S Ulrich [14].

\begin{tabular}{l|ll}
\hline $\begin{array}{l}\text { Analgesic } \\
\text { strength }\end{array}$ & \multicolumn{2}{|l}{ number of doses } \\
\cline { 2 - 3 } wall group & tree group \\
\hline Strong & 2.48 & 0.96 \\
Moderate & 3.65 & 1.74 \\
Weak & 2.57 & 5.39 \\
\hline
\end{tabular}

Even without view, the dynamic quality of daylight seems to have an intrinsic value in the healing process. Keep et al. [15] reports on a comparison between the Intensive Care Units at Plymouth and Norwich. It was found that patients from the Norwich unit which was windowless, had a much less accurate memory of their length of stay, were subject to greater problems of disorientation, and 
recovered more slowly, although the windows at Plymouth were only translucent providing daylight, but no external view.

The intrinsic value of daylight in schools has been recognised for more than a century. In "School Architecture" a manual prepared to assist in the design of urban schools following the passing of the Education Act in 1870, E R Robson [16] says rather poetically - "It is well known that the rays of the sun have a beneficial influence on the air in the room .... and are to a young child very what they are to flowers"

Much more recently the value of daylight has also been quantified in the learning environment. In a study carried out by the Heschong Mahone Group [17] in the US, using data from government learning performance tests, it was shown that for 8 to 10 year old children, annual progress in maths and English was improved from 6 to $26 \%$ for day lit spaces. The effect was observed where daylight entered via diffuse rooflights, but the largest progress was found where daylight also entered via windows.

\section{Biophilia}

"I love nature" is a phrase that covers a wide range of emotions. Responses may include a wide range of actions, from hill-walking holidays to subscriptions to the WWF, from designing buildings that look like insects, to keeping indoor plants in the office. But there is one thing in common with these diverse actions, all look outside the species of homo-sapiens and its immediate self-constructed world, for some kind of inspiration or at other times, solace. Is this just to be dismissed as sentimentality? Is nature to be seen important only if it yields raw materials for drugs, food and materials; is bio-diversity to be protected simply for the utility of the gene pool, or is this engagement of deeper significance?

In developed nations, many of us live lives highly divorced from what we chose to consider as nature. However almost wherever we look in the man-made world we still see references to nature somewhere. The question that this paper poses then, is should we actively promote and provide this - nature reserves, parks, gardens, ... natural materials, climatically responsive buildings ... down to indoor plants and pictures of distant mountains on the wall? Or should we simply respond to demand? Should Eco-architecture promote or respond.

\subsection{Nature and architecture}

If we look at primitive architecture there is much evidence of nature incorporated in both the form and the structure of the building. Indeed we can move back from the human being into animal architecture itself and see wondrous forms and intricate skills demonstrated. But it is obvious that the incorporation of a branch or a broad palm leaf or bundle of reeds bound together to make it into a useful element, is not some conscious gesture to represent nature. It is nature itself, because of the lack of anything else. It is adaptive opportunity.

Vernacular buildings rarely show "references" to nature in form or element, since, like the primitive shelter, they by necessity incorporate nature. Thus we 
see the timbers of a house with the grain and knots showing - even more impressive, the crook house, where a bent tree-trunk is sliced in two to produce a pair of matching half portals. The thatch, the wattle and daub, the tiles and bricks are all from the locality and would be materials that the occupant understood trees are felled, reeds are cut, bricks are burnt. There was no need to fashion something to look like nature, it already was nature.

By contrast, most people looking at a modern downtown building, would not know where the materials, both on the inside and out, came from or how they were produced. Even modern low rise housing plays tricks on us - slates produced from epoxy resin, autoclaved calcium silicate bricks, moulded doors imitating wood grain, the rooms lined with laminate floor, synthetic carpet, reconstituted stone worktops and sink etc, etc.

It is perhaps for this reason, our distancing from real nature, that architects and designers have become so fascinated by mimicry. Unlike the classical column this mimicry becomes symbolic by form only, not by function. Whereas the tubular steel column has a direct equivalent in the hollow stems of plants, and shares the same efficiency of material, many modern architectural manifestations of nature, as illustrated below, are purely symbolic.

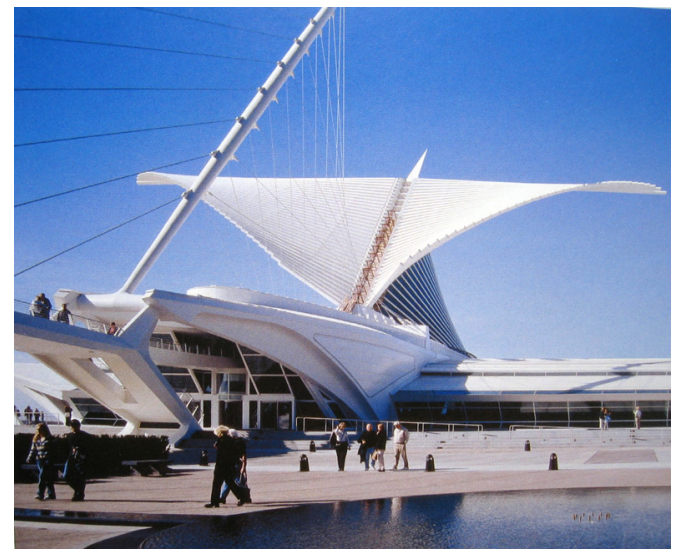

Figure 4: Milwaukee Art Museum, Wisconsin, USA by Calatrava. Although seductively evocative of nature the form is symbolic rather than functional.

\section{Implications for environmental design}

We have suggested that man has a need for environmental stimuli and a need to respond to them. If this is true, what are the implications for the design of our buildings and cities? We have also implied that these stimuli should be due to 'natural causes' and associated with the 'natural' outdoors. (But this could be simply because the positive evidence available is only from cases where the stimuli are of that type). And we have referred to this package of stimuli as ambience. 
This prompts the following questions: Is it essential to have natural ambience by contact with natural environmental diversity? Or can we create artificial ambience - where natural environmental diversity is simulated? Or even can we create synthetic ambience - were the diversity is artificial and arbitrary?

\subsection{Natural ambience}

This is the conventional 'adaptivists' view. The architectural interpretation is the adoption of shallow plan buildings, naturally ventilated and daylit with openable windows. Controls would be intuitive and sympathetic to occupant participation, and the spatial and technical design would provide variety and adaptive opportunity. Intermediate spaces such as atria, conservatories, loggia and verandas, free from active control, form a soft edge between the interior and exterior. Externally the architecture continues into the garden where the microclimate still shows a degree of moderation and the horticulture is applied with a range of artifice, but ultimately allows nature to dominate. The landscape design is influenced by its perception by the occupants of the building, rather than being seen as a setting for the building when seen from outside. The principle continues at the urban scale, with accessibility of and to wild life considered in the provision of green corridors and wild parks.

Although indoors, the occupant is placed in the natural world and the building is seen only as a mediator. And the contextual awareness does not stop at the site boundary; it is reflected in a concern for the global environment - the choice of materials and a responsible attitude to the use of energy and other resources, messages which are implied by the design of the building.

Why then, do we have to consider the issue further?

Urban growth, the coalescing of communities, seems to be driven by a force as inevitable as the law of gravity. Unlike gravity, it is not described by a simple algorithm - rather it is the result of a complex of political, cultural, functional and environmental expedients - and cannot be discussed here. The outcome however, is relevant, since together with the resulting growth of land value, it has led to an ever-increasing size of building and plan depth. This in itself removes people from the natural ambience of outside.

Just as at the end of the $19^{\text {th }}$ century the developing technologies acted as a stimulus to urbanization and the enclosure of the working environment, current technologies offer technical opportunities which creative architects find irresistible. Recent developments in materials such as glass, polymers, stainless steel, in computed structural analysis, and information technology, all facilitate the increase in size and technological complexity of the modern building. Inevitably then, the question must arise - can we do without natural ambience? Can the environmental diversity be delivered in a different way?

\subsection{Artificial and synthetic ambience}

This is nothing new; in a less technological age evocation of the outdoors was provided by painting and sculpture, spanning perceived levels of taste from fine art to the 'high-naff' of plastic flowers (with perfume!) and animated pictures of 
waterfalls. With current information technology it would not be difficult to offer a rich menu of naturalistic stimuli - images of landscapes and its inhabitants, sounds and even smells could be delivered deep into a building. This could transport the occupant to distant idyllic environs, or simply relay the real outdoor surroundings of the building. It could be accompanied by 'naturalistic' environmental stimuli such as temperature swings and modulations of luminance and colour temperature.

Simulation and virtual reality has reached an advanced state of development now used for applications as diverse as, for example, training in surgery, flying, and presenting building 'walk-throughs' from electronic moving images developed straight from CAD packages. Simulation in these circumstances is hugely successful and convincing - it is well known that airline pilots training to cope with emergencies show signs of profound stress although they are quite aware that the circumstances are not real. If this is so successful, would not the evocation of the garden outside be an easy task? But there is a difference here. In the case of the flight simulator, the illusion is the focus of interest. In contrast, the image of distant mountains projected onto the walls of a building, will have to be absorbed subliminally, if it is to achieve the quality of natural ambience.

We have made the case for environmental variance and diversity in order to stimulate adaptive behaviour. But does the variance have to relate, either directly or by artificial means, to nature. Could not the thermal, visual, and acoustic environment be modulated in an arbitrary way, and a new set of adaptive opportunities be created artificially? For example a temperature swing could be delivered by the a/c system at the same time that a strong visual event was created by the lighting system. This could then be neutralized by an action through a graphic interface on the occupant's workstation. Would this synthetic ambiance be as satisfying as walking to the window and throwing it open?

\section{Conclusions}

It appears then that our instinctive responses to the natural world are alive and well, and still make an important contribution to our health and comfort in the modern environment. However, our cultural responses have to a large part, removed us from the very nature that nurtured us. There seem to be two directions to go - embrace 'real nature' - naturally ventilated, daylit buildings, with user-controls, set in an accessible naturalized landscape into which nature is welcomed. Or, pursue an ever more technological approach - controls with automation and IT feedback, simulation, virtual reality - a science fiction future of colour therapy rooms, sensory stimulation scenarios, and personal implants programmed to give the sensation of bird-song and spring sunshine! Indeed, this scenario has been visited by many science fiction writers, one suspects cynically, rather than enthusiastically. If successful, it would give the 'advantage' of being able completely disengage from nature - there would be no limit to the height and depth of buildings, and their occupation density.

As is customary at the end of scientific papers, we say that there is need for more research. It is hoped that this paper will help make the case for a new 
field of cross-disciplinary study, bringing physics, biology, psychology and sociology, into the architecture and engineering of the built environment.

\section{References}

[1] Winston, R. Human Instinct. Bantom Press, 2002.

[2] Heschong, L. Thermal Delight in Architecture, The MIT Press, 1979.

[3] Schiller, G.E., A comparison between measured and predicted comfort in office buildings.

[4] Fanger P.O. How to apply models predicting thermal sensation and discomfort in practice in Thermal Comfort: Past, Present and Future, ed 1994.

[5] Humphreys M.A, Nicol J.F. An Adaptive Guideline for UK Office Temperatures in Standards for Thermal Comfort - Indoor Temperature Standards for the $21^{\text {st }}$ Century, ed. By F. Nicol, Humphreys 1995.

[6] Oseland N.A.1994 A Within Groups Comparison of Predicted and reported Thermal Sensation votes on Climate chambers, Offices and Homes. Proceedings of Healthy Buildings 94, Budapest, 1994.

[7] Heerwagen J. Adaptation and Coping: Occupant Response to Discomfort in Energy Efficient Buildings. Proceedings ACEEE Summer Study on Energy Efficiency in Buildings 1992.

[8] Bordass W. User and Occupant Control in Office Buildings. Proceedings ASHRAE conference on building design, technology and occupant wellbeing, Brussels, 1993.

[9] Baker N, Standeven M. Thermal Comfort for free-running buildings. Energy in Buildings 23, 1996.

[10] Guedes M. Thermal Comfort and Passive Cooling in Southern European Offices. PhD Thesis, Univ Cambridge, 2000.

[11] Merghani, A. Exploring thermal comfort and spatial diversity. In Environmental diversity in architecture. Ed. Steemers K., Steane M A, Spon Press, 2004.

[12] Nikolopoulou M, Baker N, Steemers K. Thermal Comfort in Outdoor Urban Spaces: the Human Parameter. Solar Energy 1999.

[13] Parpairi, K. Daylighting in Architecture - Quality and User Preference. PhD Thesis. Univ Cambridge, 1999.

[14] Ulrich, R S. View through a Window may influence Recovery from Surgery. Science 224. 1984.

[15] Keep P, James R, Inman M. Windows in the Intensive Therapy Unit. Anaesthesia, 35, 1980.

[16] Robson, E R., School Architecture, Leicester University Press (1972) 1874

[17] Heschong Mahone Group. Daylighting in schools. California Board of Energy Efficiency. 1999. 